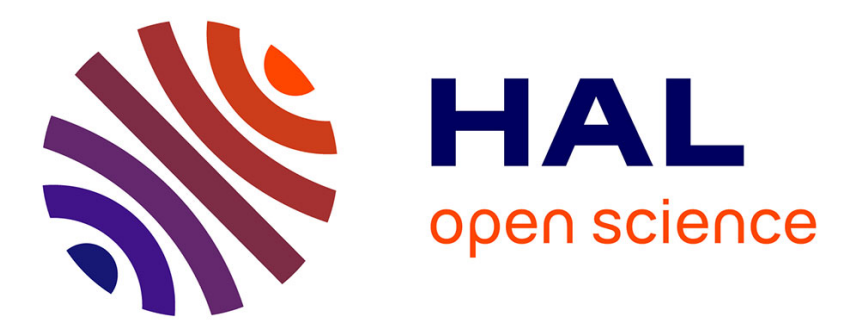

\title{
Physico-Chemical Characterization of Fine and Ultrafine Particles Emitted during Diesel Particulate Filter Active Regeneration of Euro5 Diesel Vehicles
}

\author{
B. R'Mili, A. Boreave, A. Meme, P. Vernoux, M. Leblanc, L. Noel, S. Raux, \\ B. d'Anna
}

\section{To cite this version:}

B. R'Mili, A. Boreave, A. Meme, P. Vernoux, M. Leblanc, et al.. Physico-Chemical Characterization of Fine and Ultrafine Particles Emitted during Diesel Particulate Filter Active Regeneration of Euro5 Diesel Vehicles. Environmental Science and Technology, 2018, 52 (5), pp.3312-3319. 10.1021/acs.est.7b06644 . hal-01760162

\section{HAL Id: hal-01760162 \\ https://hal.science/hal-01760162}

Submitted on 23 Oct 2018

HAL is a multi-disciplinary open access archive for the deposit and dissemination of scientific research documents, whether they are published or not. The documents may come from teaching and research institutions in France or abroad, or from public or private research centers.
L'archive ouverte pluridisciplinaire HAL, est destinée au dépôt et à la diffusion de documents scientifiques de niveau recherche, publiés ou non, émanant des établissements d'enseignement et de recherche français ou étrangers, des laboratoires publics ou privés. 
1 Physico-chemical characterization of fine and ultrafine particles emitted during 2 DPF active regeneration of Euro5 Diesel vehicles

3

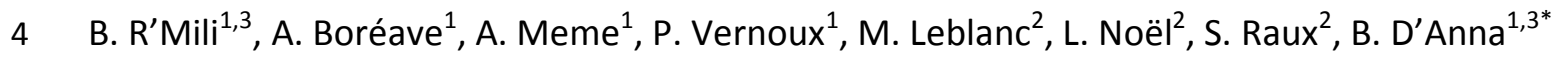

5

6

7

8

9

10

11

12

13

14

15

${ }^{1}$ Université Lyon 1, CNRS, UMR 5256, IRCELYON, Institut de recherches sur la catalyse et l'environnement de Lyon, 2 Avenue Albert Einstein, F-69626 Villeurbanne, France

${ }^{2}$ IFP Energies nouvelles - Direction Systèmes Moteurs et Véhicules, Etablissement de Lyon, Rond-point de l'échangeur de Solaize - Institut Carnot IFPEN Transports Energie- BP 3, 69360 Solaize - France

${ }^{3}$ now at the Aix-Marseille Univ, CNRS, LCE, 13003, Marseille, France

*Corresponding Author : barbara.danna@univ-amu.fr 


\section{Abstract}

Diesel Particulate Filters (DPFs) are commonly employed in modern passenger cars to comply with current particulate matter (PM) emission standards. DPFs requires periodic regeneration to remove the accumulated matter. During the process high concentration particles both in nucleation and accumulation mode are emitted. Here we report new information on particle morphology and chemical composition of fine (FPs) and ultrafine particles (UFPs) measured downstream of the Diesel Particulate Filters (DPF) during active regeneration of two Euro 5 passenger cars. The first vehicle was equipped with a closecoupled Diesel Oxidation Catalyst (DOC) and non-catalyzed DPF combined with fuel borne catalyst, the second one with DOC and a catalyzed-Diesel Particle Filter (CDPF). Differences in PM emission profiles of the two vehicles were related to different after treatments design, regeneration strategies but also vehicles characteristics and mileage. Particles in the nucleation mode consisted of ammonium bisulfate/sulfate and sulfuric acid generated, suggesting that the catalyst desulfation is the key process in the formation of UFPs. Larger particles and agglomerates, ranging from 90 to $600 \mathrm{~nm}$, consisted of carbonaceous material (soot and soot aggregates) coated by condensable material including organics, ammonium bisulfate and sulfuric acid. Particle emission in the accumulation mode was due to the reduced filtration efficiency (soot cake oxidation) throughout the regeneration process.

Keywords : DPF active regeneration, Euro5, Diesel exhaust, black carbon, ultrafine and fine particles, chemical composition, TEM-EDX, AMS.

\section{Introduction}

Motor vehicles, especially those powered by Diesel engines, have often been cited as a leading source of ambient ultrafine particles (UFPs) emission..$^{1-4}$ UFPs are defined as particles having an aerodynamic diameter of $100 \mathrm{~nm}$ or less, although they are not a major factor in mass-based particulate matter (PM) measurements in the environment, they are the dominant contributor to the overall number of particles in cities and near busy roads and highways. ${ }^{4}$ A growing concern arises in the public health community about the contribution of the UFPs to the overall health impacts of particulate matter (PM) and their ability to bypass the human body's natural respiratory filtration systems. ${ }^{5}$ Population based epidemiological studies as well as toxicological and clinical studies indicate a strong association between PM exposure and adverse health outcomes. ${ }^{6-8}$ Particles deposit in 
different parts of the lung according to their aerodynamic diameter, resulting in varying degree of toxic potency. For example, the ultrafine particle fraction may be more toxic than the accumulation or coarse mode due to their smaller sizes and higher exposed surface area that becomes available for adsorption of potentially toxic organic species. ${ }^{8,9}$ In urban areas, vehicles are a major emission source of ambient UFPs both in terms of number and mass. ${ }^{4}$ In 2012, Diesel exhaust was classified as being carcinogenic to humans (IARC group 1), as well as labeled a cause for other health concerns such as lung and heart diseases. ${ }^{10,11}$

Since 1993 European transportation regulation has focused on reducing $\mathrm{PM}$ mass, $\mathrm{CO}_{2}$ and NOx emissions. From 2011, regulation on particle number (PN) emission has been introduced (Euro5b) limiting PN to $6.0 \times 10^{11} \# / \mathrm{km}$ (particle diameter (Dp) > $23 \mathrm{~nm}$ ). ${ }^{12} \mathrm{In}$ Diesel cars, PM reduction is achieved by combining Diesel Oxidation Catalyst (DOC) and Diesel Particulate Filter (DPF). The main role of the DOC is to oxidize CO and unburnt organic compounds. The DOC, on the other hand, oxidizes $\mathrm{NO}$ to form $\mathrm{NO}_{2}$ which assists $\mathrm{PM}$ oxidation in the DPF. ${ }^{13-16}$

The operation principle of DPF systems is based on the separation of the airborne particles from the gas stream through filtration or physical deposition (i.e. inertial impaction, interception, Brownian diffusion and thermophoresis mechanisms). ${ }^{15,17-21}$

Filtration efficiency is very high and a $95 \%$ reduction PM can be easily achieved. ${ }^{22,} 23$ Continuous soot deposition on the DPF's walls forms a deep-bed "soot-cake", which significantly improves filtration efficiency. ${ }^{18,24}$ To avoid excessive back pressure on the engine, regeneration of the accumulated soot is periodically required, and it is commonly accomplished by an exothermic reaction. The so-called "active regeneration" is initiated by the post-injection in the engine's cylinders during the late expansion stroke or directly in the exhaust line in order to generate exothermic energy across the DOC. ${ }^{25-27}$

Combustion of soot by oxygen requires temperatures above $600^{\circ} \mathrm{C}$ which are rarely achieved in the exhaust of Diesel vehicles. Soot combustion temperature can be reduced by the a catalytic washcoat deposited in inlet channels of the DPF to boost NO oxidation reaction into $\mathrm{NO}_{2}$ which can oxidize soot, called catalyzed DPF (CDPF). ${ }^{28,}{ }^{29}$ Another common system, called Fuel Borne Catalyst (FBC), is based on the addition of metallic salts or organometallic compounds into the engine combustion chamber. ${ }^{23,} 30,31$ Upon combustion the additive produces nanoparticles of metal oxides which are intimately mixed with soot particles and 
stored on the DPF walls. As the regeneration process starts and the temperature rises, the oxygen of the metal oxide catalyses the oxidation of the soot layer from around $550^{\circ} \mathrm{C}$ instead of $650-700^{\circ} \mathrm{C}$ without any catalysts. ${ }^{32}$

During active regeneration process, the filter temperature sharply increases while the pressure gradually drops, due to the soot-cake combustion. ${ }^{33-35}$ This process is characterized by high emission of PM. Bimodal particle distributions are typically observed during DPF regeneration. $^{33,36-43}$ The nucleation mode has mainly been attributed to semi-volatile compounds released at high temperatures and originating from stored volatile material that combines engine lubricating oil and sulfuric acid/ sulfates ${ }^{36-39,44-46}$ or to the fragmentation of soot particle aggregates. ${ }^{33}$ A recent study reported direct evidence of gaseous sulfuric acid (GSA) emissions in modern Diesel engines exhaust. ${ }^{47}$ GSA emissions increased with sulfur containing fuel but also during high engine load, when catalyst temperature is high. ${ }^{47}$ The accumulation mode during DPF regeneration was mainly associated to carbonaceous soot particles coated with small fraction of ash and organic compounds. ${ }^{33,35}$

The quantification of the volatile fraction of particles in car exhaust is not straightforward and can be strongly affected by condensation and coagulation phenomena, sometimes not originating in the engine but in the sampling installation. ${ }^{48}$ Despite these difficulties, the impact of exhaust PM on air pollution and human health cannot be properly assessed without a better estimation of this volatile fraction. Here, we report PM measurements during the DPF active regeneration of two Euro5 Diesel cars equipped with most commonly used after-treatment devices at a chassis dynamometer test bench. A new analytical approach was adopted and provided access to novel physico-chemical and morphological features of the fine and ultrafine particles emitted (including the PM volatile fraction). A compact Time-of-Flight Aerosol Mass spectrometer (c-ToF-AMS, Aerodyne Inc. USA) was used to investigate size-resolved mass spectra of the volatile PM fraction. Particle morphology and elemental composition were investigated sampling at specific times through porous TEM grids using the mini particle sampler (MPS).

\section{Experimental set-up and methodology}

\subsection{Vehicles and fuels specification}


111 Two vehicles with different Diesel engines and after treatment technologies were evaluated 112 during the testing phases; both were equipped with a common-rail direct injection and meet 113 Euro 5 emission standard.

1. Vehicle 1: fitted with a close coupled DOC and non-catalyzed DPF combined with a Fuel Borne Catalyst (FBC-DPF).

2. Vehicle 2: fitted with two DOCs and a catalyzed DPF (CDPF).

The main vehicles characteristics are summarized in Table 1. The after-treatment configurations evaluated in this study corresponded to the most widespread Euro5 technologies and Diesel exhaust control configurations for passenger cars. The fuel used during the experiments met the EN590 standard representative of current commercial fuels with low sulfur content less than $2 \mathrm{mg} / \mathrm{kg}$.

\subsection{Measurement protocol}

The tests were conducted at IFP Energies nouvelles facility. Dedicated instrumentation was deployed at the dynamometer test bench to follow exhaust emissions (exhaust composition particle number, particle composition and morphology) and vehicle parameters (vehicle speed, exhaust gases temperature and pressure, pressure drop across the DPF) in order to characterize the active regeneration process of the two DPFs. The schematic of the experimental set-up is shown in Figure 1.

The exhaust was sampled using a two-stage dilution and sampling system with perforated tube and ejector diluter (FPS-4000 Dekati ). The FPS-4000 was used with a dilution ratio of about $7: 1$, calculated from the $\mathrm{CO}_{2}$ concentrations continuously measured in the exhaust line and downstream of the FPS-4000 corresponding to sampling rate of about $21 \mathrm{~L} / \mathrm{min}$. The FPS dilution system allows to sample at the tailpipe using constant temperature and dilution ratios. It can therefore provide a better assessment of the volatile fraction of PM with respect to the CVS where PM emission are measured using variable dilution ratios and temperatures. $^{49}$

Particulate emissions were monitored by several instruments. A Scanning Mobility Particle Sizer with Faraday Cup Electrometer (SMPS+E GRIMM) equipped with a small Differential Mobility Analyzer (Vienna Type DMA) was chosen for particle number concentration and size distribution measurements. Particles were charged using an annular dielectric barrier 
discharge. The SMPS+E was operated with a sheath air flow of $3 \mathrm{~L} / \mathrm{min}$ and an aerosol flow of $0.3 \mathrm{~L} / \mathrm{min}$. Aerosols size distribution measurements between 2 and $35 \mathrm{~nm}$ were achieved every 37 seconds. Data inversion is done according to the standard ISO 15900 (standard 2009).

On-line time resolved measurements of sub-micrometer particle composition were performed using a compact time-of-flight (c-TOF Tofwerk) aerosol mass spectrometer (AMS, Aerodyne Inc. USA). The AMS operating principles, calibration procedures and analysis protocols are described in details elsewhere. ${ }^{50,51}$ The instrument provides quantitative sizeresolved mass spectra of the non-refractory components empirically defined as vaporizable species over a $1 \mathrm{~s}$ time interval at $700^{\circ} \mathrm{C}$ and $10^{-7}$ torr. ${ }^{51}$ These typically include organic matter, ammonium nitrate and sulfate, chloride and water. This instrument combines the mass spectrometer system with aerodynamic particle sizing and thus provides information on the aerodynamic size distribution of particles. Particles were sampled through a critical orifice of $100 \mu \mathrm{m}$ at approximately $85 \mathrm{~mL} / \mathrm{min}$. C-ToF-AMS data analysis was done with AMS Analysis Toolkit Squirrel v.1.57. using Squirrel software and a cumulative peak fitting and iterative residual analysis. ${ }^{52}$ The inlet system has $100 \%$ transmission efficiency of particles in the vacuum aerodynamic diameter range $70-500 \mathrm{~nm}$ and partial transmission of particles in the $25-70 \mathrm{~nm}$ and $500 \mathrm{~nm}-1.5 \mu \mathrm{m}$ ranges. The instrument was calibrated with ammonium nitrate particles. Gas-phase corrections were made by HEPA-filtered air sampled at the beginning or the end of each test.

A Thermo Scientific Model 5012 MAAP (Multi-Angle Absorption Photometer) was used for Black Carbon (BC) mass concentration measurements of vehicle 2 (FBC-DPF) at a single nominal wavelength at $670 \mathrm{~nm}$. The instrument measures both light attenuation and scattering at specific angles $0^{\circ}, 130^{\circ}$ and $165^{\circ}$ reducing significantly the influence of scattering, even if material other than $\mathrm{BC}$ is also sampled in the filter. ${ }^{53}$ The technique has been mainly applied to ambient measurements but it has also been successfully deployed to combustion particles. ${ }^{53}$ Correction for measurement artifacts at high BC mass concentration levels were taken into account as suggested by Hyvarinen et al. ${ }^{54}$

A mini-particle sampler (MPS) was used to collect exhaust particles. This technique, based on filtration through TEM-porous grids, enables sampling of particles directly on a specific support minimizing additional sample preparation procedure and sampling artifact. ${ }^{55} \mathrm{~A}$ solenoid valve system was used to perform sampling at specific times of the regeneration 
events with a flow rate of $0.3 \mathrm{l} / \mathrm{min}$. The deposited particles were then investigated by TEM, coupled with energy-dispersive X-ray (EDX) with respect to their size, morphology and elemental composition (JEOL 2010F microscope operated at $200 \mathrm{kV}$ ).

\subsection{Test plan}

To verify DPF regeneration repeatability three regenerations were performed for each vehicle. One after the vehicle arrival, thereafter, the DPF was loaded driving for approximately $600 \mathrm{~km}$ on random successive cycles (10 New European Driving Cycle (NEDC), 6 World harmonized Light-duty Test Cycle (WLTC), 4 Common Artemis Driving Cycle (CADC) and 12 urban part of CADC, steady speed haulages arose from the NEDC and with different conditions of engine starts (from cold to hot)). A random order of driving cycles was implemented to avoid systematic bias. A decoy was then applied to the DPF back pressure sensor to simulate an increase in the DPF loading and the need of a DPF cleaning. This decoy forced the engine control unit (ECU) to initiate an active regeneration process and to switch to the dedicated strategy once the pressure drop before and after the DPF increased. The DPF regenerations were always initiated at constant vehicle speed of about $90 \mathrm{~km} / \mathrm{h}$. The engine load remained constant during the whole regeneration process and was set to achieve an upstream DPF temperature of about $390{ }^{\circ} \mathrm{C}$, in order to characterize the regeneration process with similar and stable initial conditions for both DPFs. Figure 1 shows the schematic of experimental set-up at the chassis dynamometer test bench.

\section{Results and Discussion}

As mentioned above, three regenerations were realized for each vehicle, for brevity, only the results from the first regeneration of each vehicle will be presented and discussed in details here. The second and the third regenerations showed very strong similarities, therefore, only the second ones are reported in the Supplementary Information (SI) document. Temporal evolution of the volatile fraction of PM monitored by a cTOF-AMS together with methane (tracer for the post injection) and temperature profile upstream DPF are reported in Figure $2 \mathrm{a}$ and $2 \mathrm{~b}$ for the FBC-DPF and CDPF vehicles, respectively. Temperature profiles for the two vehicles (brown line) are slightly different even if the average upstream DPF temperature is approximately $610^{\circ} \mathrm{C}$. Temperature variability can 
have various causes, such as different conductivity of the DPF material and/or different length of exhaust lines, position in the pipe and different post-injection strategy. For the FBC-DPF vehicle (Figure 2a), the temperature first quickly increased up to $600{ }^{\circ} \mathrm{C}$, followed by slower increase to $630^{\circ} \mathrm{C}$ and a oscillatory behavior between $600{ }^{\circ} \mathrm{C}$ and $630{ }^{\circ} \mathrm{C}$ until postinjection end. Such temperature oscillations are most probably due to the regulation of the fuel post-injection in order to guarantee the required regeneration temperature and to avoid filter breakup. For the CDPF vehicle (Figure b), as the catalytic after-treatment is located in close-coupled, a sharp increase of temperature up to $620^{\circ} \mathrm{C}$ was observed involving a temperature overshoot at the beginning of the regeneration process before stabilization at $610^{\circ} \mathrm{C}$.

Regeneration of the FBC-DPF vehicle (Figure 2a) generated a progressive emission of PM composed of BC (black line) up to a maximum value of $450 \mu \mathrm{g} / \mathrm{m}^{3}$, condensable material up to $85 \mu \mathrm{g} / \mathrm{m}^{3}$ at the end of regeneration. The condensable fraction of particles was composed by inorganic material (ammonium bisulfate, sulfuric acid, traces of nitrate) and organic material. The pie chart in Figure 2a shows the relative weight percentage of each volatile species : bisulfate $51 \%$, organics $28 \%$, ammonium $10 \%$, sulfuric acid $8 \%$ and nitrate $3 \%$, averaged during 600 seconds from the regeneration start. Good filtration efficiency, close to $90 \%$, calculated using BC data, was rapidly restored after post-injection end. BC emissions dropped to $50-60 \mathrm{\mu g} / \mathrm{m}^{3}$ and remained stable for 1800 seconds then the engine was turned off. AMS measurement were interrupted just after the DPF regeneration end. Figure S2 shows the good repeatability of $B C$ emission for the three regenerations of the FBC-DPF vehicle. $\mathrm{BC}$ time profiles were explained by the reduced filtration efficiency of the DPF due to the oxidation of the soot layer throughout the regeneration. The required time to rebuild the soot cake is related to both soot concentration in the exhaust and DPF walls porosity. ${ }^{33,}$ ${ }^{45}$ Figure S1a shows the time profile and chemical composition of the condensable fraction observed for the second regeneration. A very similar time profile was observed even if considerable less sulfur containing particles were emitted during the second regeneration.

The CDPF vehicle, Figure $2 b$, was characterized by high particle emission in the first minutes of the DPF regeneration. The condensable fraction reached a maximum mass loading of 150 $\mu \mathrm{g} / \mathrm{m}^{3}$ of bisulfate, ammonium, sulfuric acid and organic just after the regeneration start. The pie chart in Figure $2 \mathrm{~b}$ shows the relative weight percentage of each volatile species : 
bisulfate $52 \%$, organics $29 \%$, sulfuric acid $11 \%$ and ammonium $8 \%$, averaged during 600 seconds. The organic fraction was relatively stable for the first 800 seconds, then slowly decreases for almost 800 seconds, at the end the engine was turned off. No black carbon measurements were available for this vehicle. The second regeneration of the CDPF vehicle is presented in Figure S1b: a first small burst of particles enriched in nitrate and organics is observed for the first two minutes, followed by the emission of high loading of sulfur containing particles and in minor extent organics. The sharp increase of temperature up to $620^{\circ} \mathrm{C}$ involving a temperature overshoot can tentatively explain the initial burst of particles seen in Figure $1 \mathrm{Sb}$. Particle were also emitted after the post-injection end, but for a relatively short time.

For both vehicles acidic particles were measured during the DPFs regeneration. Average mass spectra for the condensable fraction of particles and the corresponding mass spectra of the organic fraction only, are shown in Figures S3 and S4, SI document. The organic fraction, Figure S4a and S4b, is dominated by the ion fragments $\mathrm{C}_{n} \mathrm{H}_{+2 n+1}(\mathrm{~m} / \mathrm{z} 29,43,57,71,85,99 \ldots)$, typical of normal and branched alkanes and $\mathrm{CnH}_{+2 n-1}(\mathrm{~m} / \mathrm{z} 27,41,55,69,83,97,111 \ldots)$ and $\mathrm{C}_{n} \mathrm{H}_{+2 n-3}$ $(\mathrm{m} / \mathrm{z} 67,79,81,95,107,109, .$.$) typical of cycloalkanes. { }^{56,57}$ Lower intensity is observed for the ion fragments $\mathrm{C}_{6} \mathrm{H}_{5} \mathrm{C}_{n} \mathrm{H}_{+2 n}(\mathrm{~m} / \mathrm{z} 77,91,105,119 \ldots)$ typical of aromatics. Reference spectra of the nebulized lubricant oil for the FBC-DPF and CDPF vehicles, and the mass spectrum of the nebulized fuel, used for both vehicles, are presented in the figures S5a, 5b and S6, SI document. By comparison of all these spectra it can be concluded that the organic fraction emitted during DPF regeneration resembled rather the fuel post-injection than lubricant oil. Table S1 shows the elemental composition (ICP-MS analysis) of the lubricant oils. Sulfur content ranged between 0.14 and 0.12 weight \% for FBC-DPF and CDPF vehicles, respectively. Only molybdenum was found in substantial higher amount in the CDPF lubricant oil.

Figures $3 a$ and $3 b$ show the evolution of the UFPs size distribution and concentration between 4-35 nm measured at the DPFs outlet of both vehicles, as well as the DPF upstream temperature. As the post-injection started, a gradual increase in UFPs concentration, with mobility diameter around 7-15 nm, was observed for the FBC-DPF vehicle (Figure 3a), whereas for the CDPF vehicle (Figure 3b), a rapid increase of particle concentration with mobility diameter of 20-30 nm was observed. In both cases, ultrafine particle emission was 
observed as long as the active regeneration process took place. This duration, more or less 8-9 minutes, is likely related to the post-injection strategy, which relies on the estimated DPF soot load, traffic conditions met by the vehicle and fuel savings strategy.

In Figure 4 we further investigated the nature of the emitted particles combining aerosol mass spectrometry and TEM techniques. AMS chemically resolved mass normalized particle Time-of-Flight (pToF) size distributions for the FBC-DPF are shown in Figure 4a, 4b and 4c. Figure $4 \mathrm{a}$ at the very beginning of the DPF regeneration catches a burst of nucleating particles with aerodynamic vacuum diameter of $25 \mathrm{~nm}\left(D_{v a}\right)$ composed by bisulfate, ammonium, sulfuric acid and an organic fraction. A second and broader mode between $100-$ $800 \mathrm{~nm}$ dominated by the organic fraction is also observed. Transmission of particles below $70 \mathrm{~nm}$ is relatively poor in the AMS due to particle losses in the aerodynamic lens. ${ }^{51}$ Nevertheless, the instrument was able to monitor the presence of nucleating particles with aerodynamic diameter of $25 \mathrm{~nm}$. Figure $4 \mathrm{~b}$ shows the particle size distribution 240 seconds after the regeneration start, the nucleation mode is still present together with the broad mode enriched in bisulfate and organic material. A TEM image of the same time period, figure $4 d$, shows the appearance of soot in form of fractals and agglomerates, and the presence of droplets of condensable material ranging from $15-20 \mathrm{~nm}$ to $100 \mathrm{~nm}$, probably partly adsorbed onto the soot particles. The last period of the DPF regeneration is shown in the figures $4 \mathrm{c}, 4 \mathrm{e}$ and $4 \mathrm{f}$. The AMS pTof plot shows the broad particle mode composed by bisulfate, organic material and some sulfuric acid. TEM images (figure $4 \mathrm{e}$ and $4 \mathrm{f}$ ) show an increasing amount of $\mathrm{BC}$, consistent with the observations presented in figure $2 \mathrm{a}$, and still the presence of small liquid droplets.

Chemically resolved particle size distribution from AMS measurements of the CDPF vehicle are shown in Figure 5a. A nucleation mode was observed for the first two minutes of DPF regeneration owning an average aerodynamic vacuum diameter of $28 \mathrm{~nm}$. The chemical composition indicated the presence of ammonium bisulfate, sulfuric acid, and organic matter. Figures $5 d$ shows a TEM image sampled at the beginning of the DPF regeneration, many small droplets (liquid particles) owing a diameter of about $20 \mathrm{~nm}$ (geometric diameter) were observed. Figure $5 b$ shows a bimodal distribution, the persistent nucleation mode and an accumulation mode mainly composed by organic material and sulfate, partly adsorbed onto soot particles. This was confirmed by Figure $5 d$ where the both liquid droplets and 
fractal soot covered by liquid droplets were observed. The liquid fraction easily evaporated under the TEM electron beam, as can be seen in Figure 5e. Soot was observed only after few minutes from the start of the regeneration, probably when the soot-cake was removed. No big soot agglomerates were observed during the regeneration. Figure $5 c$ shows the particles chemical composition and size distribution during post-regeneration, 900 seconds after the beginning of the DPF regeneration.

The nucleating particles observed during both DPFs regeneration were composed of condensable material mainly by sulfuric acid and bisulfate/sulfate which was partially neutralized by ammonia and an additional organic condensable fraction (as said before from the post-injection). The presence of traces of ammonia, even at pptv level, has been shown to enhance nucleation rate by orders of magnitude via ternary nucleation process. ${ }^{58,59}$

Our results on the chemical and morphological nature of the nucleating particles complete and support the observations of Arnold and co-workers, where gaseous sulfuric acid (GSA) was identified as key precursor in the UFPs formation for engines equipped with DPF. Furthermore, the authors modeled particle size distribution using the measured GSA concentrations and showed that the observed particle size distribution could be reproduced only introducing condensable organic material, ${ }^{47}$ which was actually observed in our measurements. TEM and AMS analysis of the UFPs emitted during Euro5 DPF regeneration are consistent with previous works suggesting that at high temperatures, sulfur from fuel as well from lubricating oil previously stored on the catalyst surface, is released as $\mathrm{SO}_{2}$,

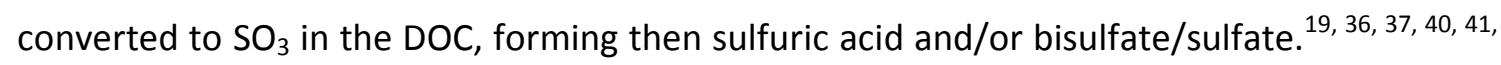
$45,47,60-62$

The major conclusions drawn from the present investigations are as follows. The active regeneration of Euro5 vehicles produced significant emissions of the particles both in terms of total number and total mass concentration, reaching up to $400-500 \mu \mathrm{g} / \mathrm{m}^{3}$ of $B C$ and 80 $150 \mu \mathrm{g} / \mathrm{m}^{3}$ of semi-volatile material (inorganic and organic). Ultrafine particles (below 25-30 $\mathrm{nm}$ ) consisted of small droplets of sulfuric acid and ammonium bisulfate/sulfate and, to a minor extent, of organic material, most likely coming from the post-injection. Desulfation of the catalyst was identified as the key process in the formation of UFPs as their generation ended as soon the temperature in the after-treatment devices was reduced. Soot particles 
327

328

329

330

331

332

333

334

335

336

337

338

339

340

341

342

343

344

345

346

347

348

349

350

351

352

353

were observed in the accumulation mode and bigger agglomerates, this latter for the FBCDPF vehicle only. Particles in the accumulation mode were emitted few minutes after the start of the regeneration process, once the soot-cake was removed causing reduced DPF filtration efficiency. The particle emission profiles and size distribution for the FBC-DPF and the CDPF vehicles were quite different and can be explained by different factors : different exhaust after-treatment design and regeneration strategies but also vehicles characteristics (such as engine, catalysts technologies, volumes and locations, actuators, different mileages), and should not be related to the after-treatment technology only. Nevertheless it can be already concluded that in order to minimize high particle concentration, regeneration strategies should avoid full removal of the soot cake. This work, based on an original analytical approach, allowed a better assessment of particle emission during regeneration of two Euro 5 light-duty vehicles equipped with the most commonly used after treatment systems. The results provide new information on morphology, size distribution, chemical composition and dynamics of particle emission during DPF regeneration.

\section{Acknowledgements}

The authors would like to thank the ADEME agency for financing support in the framework of the research project CAPPNOR (ADEME conventions 1166C0084 CORTEA program). The authors would also like to thank the Electron Microscopy facility at IRCELYON.

\section{Supporting Information}

Time series and pie chart relative to the second DPF regeneration for both vehicles, BC time profiles for three DPF regenerations (FBC-DPF vehicle), average mass spectra of the semi-volatile and organic fraction of the particles emitted during the first regeneration, mass spectra of the lubricating oil and the TAE fuel used for both vehicles. 


\section{References}

1. Argyropoulos, G.; Samara, C.; Voutsa, D.; Kouras, A.; Manoli, E.; Voliotis, A.; Tsakis, A.; Chasapidis, L.; Konstandopoulos, A.; Eleftheriadis, K., Concentration levels and source apportionment of ultrafine particles in road microenvironments. Atmos. Environ. 2016, 129, 68-78.

2. Hama, S. M. L.; Cordell, R. L.; Kos, G. P. A.; Weijers, E. P.; Monks, P. S., Sub-micron particle number size distribution characteristics at two urban locations in Leicester. Atmos. Res. 2017, 194, 1-16.

3. Hofman, J.; Staelens, J.; Cordell, R.; Stroobants, C.; Zikova, N.; Hama, S. M. L.; Wyche, K. P.; Kos, G. P. A.; Van Der Zee, S.; Smallbone, K. L.; Weijers, E. P.; Monks, P. S.; Roekens, E., Ultrafine particles in four European urban environments: Results from a new continuous long-term monitoring network. Atmos. Environ. 2016, 136, 68-81.

4. Morawska, L.; Ristovski, Z.; Jayaratne, E. R.; Keogh, D. U.; Ling, X., Ambient nano and ultrafine particles from motor vehicle emissions: Characteristics, ambient processing and implications on human exposure. Atmos. Environ. 2008, 42, (35), 8113-8138.

5. HEI Review panel on ultrafine particles. Understanding the health effects of ambient ultrafine particles; Boston, MA, USA, 2013.

6. Pope, C. A.; Dockery, D. W., Health effects of fine particulate air pollution. J. Air Waste Manag. 2006, 56 (6), 709-742.

7. Laden, F.; Neas, L. M.; Dockery, D. W.; Schwartz, J., Association of fine particulate matter from different sources with daily mortality in six US cities. Environ. Health Perspect. 2000, 108, (10), 941-947.

8. Li, N.; Sioutas, C.; Cho, A.; Schmitz, D.; Misra, C.; Sempf, J.; Wang, M. Y.; Oberley, T.; Froines, J.; Nel, A., Ultrafine particulate pollutants induce oxidative stress and mitochondrial damage. Environ. Health Perspect. 2003, 111, (4), 455-460.

9. Oberdorster, G., Toxicology of Ultrafine particles: in vivo studies. Philos. Trans. R. Soc. London, A 2000, 358, (1775), 2719-2739.

10. IARC Diesel and gasoline engine exhausts and some nitroarenes; International Agency for Research on Cancer: Lyon, France, 2013.

11. IARC Diesel Engine Exhaust Carcinogenic; Lyon, France, 2012.

12. EU 2008, REGULATION (EC) No 715/2007 OF THE EUROPEAN PARLIAMENT AND OF THE COUNCIL. In European Commission, Ed. Official Journal of the European Union, 2008; Vol. (EC) No 692/2008

13. Haralampous, O.; Koltsakis, G.; Samaras, Z.; Vogt, C.-D.; Ohara, E.; Watanabe, Y.; Mizutani, T. Reaction and diffusion phenomena in catalyzed diesel particulate filters; 2004.

14. Kandylas, I. P.; Koltsakis, G. C., NO2-assisted regeneration of diesel particulate filters: a modeling study. Ind. Eng. Chem. Res. 2002, 41, (9), 2115-2123.

15. Konstandopoulos, A. G.; Kostoglou, M.; Skaperdas, E.; Papaioannou, E.; Zarvalis, D.; Kladopoulou, E. Fundamental studies of diesel particulate filters: transient loading, regeneration and aging; 0148-7191; SAE Technical Paper: 2000.

16. Shrivastava, M.; Nguyen, A.; Zheng, Z.; Wu, H.-W.; Jung, H. S., Kinetics of soot oxidation by NO2. Environ. Sci. Technol. 2010, 44, (12), 4796-4801.

17. Adler, J., Ceramic Diesel Particulate Filters. Int. J. Appl. Ceramic Technol. 2005, 2, (6), 429-439.

18. Choi, S.; Oh, K.-C.; Lee, C.-B., The effects of filter porosity and flow conditions on soot deposition/oxidation and pressure drop in particulate filters. Energy 2014, 77, 327-337.

19. Herner, J. D.; Hu, S.; Robertson, W. H.; Huai, T.; Chang, M.-C. O.; Rieger, P.; Ayala, A., Effect of advanced aftertreatment for PM and NO $\mathrm{x}$ reduction on heavy-duty diesel engine ultrafine particle emissions. Environ. Sci. Technol. 2011, 45, (6), 2413-2419.

20. Mayer, A., Particle filter retrofit for all diesel engines. Book Expert-Verlag GmbH: 2008.

21. Wade, W. R.; White, J.; Florek, J. Diesel particulate trap regeneration techniques; 0148-7191; SAE Technical Paper: 1981.

22. Burtscher, H., Physical characterization of particulate emissions from diesel engines: a review. J. Aerosol Sci. 2005, 36, (7), 896-932.

23. Majewski, W. A.; Khair, M. K. Diesel emissions and their control; SAE Technical Paper: 2006. 
24. Konstandopoulos, A. G.; Papaioannou, E., Update on the science and technology of diesel particulate filters. Kona Powder Part.J. 2008, 26, 36-65.

25. Fino, D.; Specchia, V., Open issues in oxidative catalysis for diesel particulate abatement. Powder Technol. 2008, 180, (1), 64-73.

26. Salvat, O.; Marez, P.; Belot, G. Passenger car serial application of a particulate filter system on a common rail direct injection diesel engine; 0148-7191; SAE Technical Paper: 2000.

27. Van Setten, B. A.; Makkee, M.; Moulijn, J. A., Science and technology of catalytic diesel particulate filters. Cat. Rev. 2001, 43, (4), 489-564.

28. Setiabudi, A.; Makkee, M.; Moulijn, J. A., The role of NO2 and O-2 in the accelerated combustion of soot in diesel exhaust gases. App. Cat. B-Environ. 2004, 50, (3), 185-194.

29. Twigg, M. V., A.J.J. Wilkins, N.S. Will Emission Control. In US6294141 (B1), 2001.

30. Ntziachristos, L.; Samaras, Z.; Zervas, E.; Dorlhène, P., Effects of a catalysed and an additized particle filter on the emissions of a diesel passenger car operating on low sulphur fuels. Atmos. Environ. 2005, 39, (27), 4925-4936.

31. Song, J.; Wang, J.; Boehman, A. L., The role of fuel-borne catalyst in diesel particulate oxidation behavior. Combust. Flame 2006, 146, (1-2), 73-84.

32. Zhang, Z.; Han, D.; Wei S.; Zhang Y., Determination of active site densities and mechanisms for soot combustion with $\mathrm{O} 2$ on Fe-doped $\mathrm{CeO} 2$ mixed oxides J. Catal. 2010, 276, 16-23.

33. Beatrice, C.; Iorio, S. D.; Guido, C.; Napolitano, P., Detailed characterization of particulate emissions of an automotive catalyzed DPF using actual regeneration strategies. Exp. Therm. Fluid Sci. 2012, 39, (0), 45-53.

34. Ko, J.; Si, W.; Jin, D.; Myung, C.-L.; Park, S., Effect of active regeneration on time-resolved characteristics of gaseous emissions and size-resolved particle emissions from light-duty diesel engine. J. Aerosol Sci. 2016, 91, 62-77.

35. Cauda, E.; Hernandez, S.; Fino, D.; Saracco, G.; Specchia, V., PM0.1 Emissions during Diesel Trap Regeneration. Environ. Sci. Technol. 2006, 40, (17), 5532-5537.

36. Bergmann, M.; Kirchner, U.; Vogt, R.; Benter, T., On-road and laboratory investigation of low-level PM emissions of a modern diesel particulate filter equipped diesel passenger car. Atmos. Environ. 2009, 43, (11), 1908-1916.

37. Bikas, G.; Zervas, E., Regulated and Non-Regulated Pollutants Emitted during the Regeneration of a Diesel Particulate Filter. Energy and Fuels 2007, 21, (3), 1543-1547.

38. Campbell, B.; Peckham, M.; Symonds, J.; Parkinson, J.; Finch, A. Transient Gaseous and Particulate Emissions Measurements on a Diesel Passenger Car including a DPF Regeneration Event; 01487191; SAE Technical Paper: 2006.

39. Dwyer, H.; Ayala, A.; Zhang, S.; Collins, J.; Huai, T.; Herner, J.; Chau, W., Emissions from a diesel car during regeneration of an active diesel particulate filter. J. Aerosol Sci. 2010, 41, (6), 541-552.

40. Giechaskiel, B.; Munoz-Bueno, R.; Rubino, L.; Manfredi, U.; Dilara, P.; De Santi, G.; Andersson, J. Particle Measurement Programme (PMP): Particle Size and Number Emissions Before, During and After Regeneration Events of a Euro 4 DPF Equipped Light-Duty Diesel Vehicle; 0148-7191; SAE Technical Paper: 2007.

41. Guo, G.; Xu, N.; Laing, P. M.; Hammerle, R. H.; Maricq, M. M. Performance of a catalyzed diesel particulate filter system during soot accumulation and regeneration; 0148-7191; SAE Technical Paper: 2003.

42. Mathis, U.; Mohr, M.; Forss, A. M., Comprehensive particle characterization of modern gasoline and diesel passenger cars at low ambient temperatures. Atmos. Environ. 2005, 39, (1), 107-117.

43. Mohr, M.; Forss, A. M.; Lehmann, U., Particle emissions from diesel passenger cars equipped with a particle trap in comparison to other technologies. Environ. Sci. Technol. 2006, 40, (7), 23752383.

44. Biswas, S.; Verma, V.; Schauer, J. J.; Cassee, F. R.; Cho, A. K.; Sioutas, C., Oxidative Potential of Semi-Volatile and Non Volatile Particulate Matter (PM) from Heavy-Duty Vehicles Retrofitted with Emission Control Technologies. Environ. Sci. Technol. 2009, 43, (10), 3905-3912. 
45. Cauda, E.; Fino, D.; Saracco, G.; Specchia, V., Secondary nanoparticle emissions during diesel particulate trap regeneration. Top. Catal. 2007, 42-43, (1-4), 253-257.

46. Yamada, H.; Inomata, S.; Tanimoto, H., Mechanisms of Increased Particle and VOC Emissions during DPF Active Regeneration and Practical Emissions Considering Regeneration. Environ. Sci. Technol. 2017, 51, (5), 2914-2923.

47. Arnold, F.; Pirjola, L.; Ronkko, T.; Reichl, U.; Schlager, H.; Lahde, T.; Heikkila, J.; Keskinen, J., First Online Measurements of Sulfuric Acid Gas in Modern Heavy-Duty Diesel Engine Exhaust: Implications for Nanoparticle Formation. Environ. Sci. Technol. 2012, 46, (20), 11227-11234.

48. Giechaskiel, B.; Mamakos, A.; Andersson, J.; Dilara, P.; Martini, G.; Schindler, W.; Bergmann, A., Measurement of automotive nonvolatile particle number emissions within the European legislative framework: A review. Aerosol Sci. Technol. 2012, 46, (7), 719-749.

49. Louis, C., Y. Liu, S. Martinet, B. D’Anna, A. Martinez Valiente, A. Boreave, B. R'Mili, P. Tassel, P. Perret, M. André, Dilution effects on ultrafine particle emissions from Euro 5 and 1 Euro 6 diesel and 2 gasoline vehicles. Atmos. Environ. 2017, 169, (1), 80-88.

50. Drewnick, F., S. S. Hings, M. R. Alfarra, A. S. H. Prevot, and S. Borrmann Aerosol quantification with the Aerodyne Aerosol Mass Spectrometer: detection limits and ionizer background effects. Atmos. Meas. Techn. 2009 2, (1), 33-46.

51. Drewnick, F.; Hings, S. S.; DeCarlo, P.; Jayne, J. T.; Gonin, M.; Fuhrer, K.; Weimer, S.; Jimenez, J. L.; Demerjian, K. L.; Borrmann, S., A new time-of-flight aerosol mass spectrometer (TOF-AMS)Instrument description and first field deployment. Aerosol Sci. Technol. 2005, 39, (7), 637-658.

52. Muller, M.; George, C.; D'Anna, B., Enhanced spectral analysis of C-TOF Aerosol Mass Spectrometer data: Iterative residual analysis and cumulative peak fitting. Int. J. Mass Spectrom. 2011, 306, (1), 1-8.

53. Petzold, A.; Schonlinner, M., Multi-angle absorption photometry - a new method for the measurement of aerosol light absorption and atmospheric black carbon. J. Aerosol Sci. 2004, 35, (4), 421-441.

54. Hyvärinen, A.-P.; Vakkari, V.; Laakso, L.; Hooda, R.; Sharma, V.; Panwar, T.; Beukes, J.; van Zyl, P.; Josipovic, M.; Garland, R., Correction for a measurement artifact of the Multi-Angle Absorption Photometer (MAAP) at high black carbon mass concentration levels. Atmos. Meas. Techn. 2013, 6, 81-90.

55. R'mili, B.; Le Bihan, O. L. C.; Dutouquet, C.; Aguerre-Charriol, O.; Frejafon, E., Particle Sampling by TEM Grid Filtration. Aerosol Sci. Technol. 2013, 47, (7), 767-775.

56. Tobias, H. J., Beving, D. E., Ziemann, P. J., Sakurai, H., Zuk, M., McMurry, P., Zarling, D., Waytulonis, R., and Kittleson, D. B. , Chemical Analysis of Diesel Engine Nanoparticles Using a Nano-DMA/Thermal Desorption Particle Beam Mass Spectrometer. Environ. Sci. Technol. 2001, 35, 2233-2243.

57. McLafferty, F. W., and Turecek, F., Interpretation of Mass Spectra. 1993, University Science Books, Mill Valley, CA.

58. Coffman, D. J., and Hegg, D. A., A preliminary study of the effect of ammonia on particle nucleation in the marine boundary layer. J. Geophys. Res.Atmos. 1995, 100, 7147-7160.

59. Korhonen, P., Kulmala, M., Laaksonen, A., Viisanen, Y., McGraw, R., Seinfeld, J.H., Ternanry nucleation of H2SO4, NH3 and $\mathrm{H} 2 \mathrm{O}$ in the atmosphere. J. Geo. Res. 1999, 104, (D21), 2634926353.

60. Liang, C. Y.; Baumgard, K. J.; Gorse, R. A.; Orban, J. E.; Storey, J. M.; Tan, J. C.; Thoss, J. E.; Clark, W. Effects of diesel fuel sulfur level on performance of a continuously regenerating diesel particulate filter and a catalyzed particulate filter; 0148-7191; SAE Technical Paper: 2000.

61. Matti Maricq, M., Chemical characterization of particulate emissions from diesel engines: A review. J. Aerosol Sci. 2007, 38, (11), 1079-1118.

62. Swanson, J.; Kittelson, D., Evaluation of thermal denuder and catalytic stripper methods for solid particle measurements. J. Aerosol Sci. 2010, 41, (12), 1113-1122. 


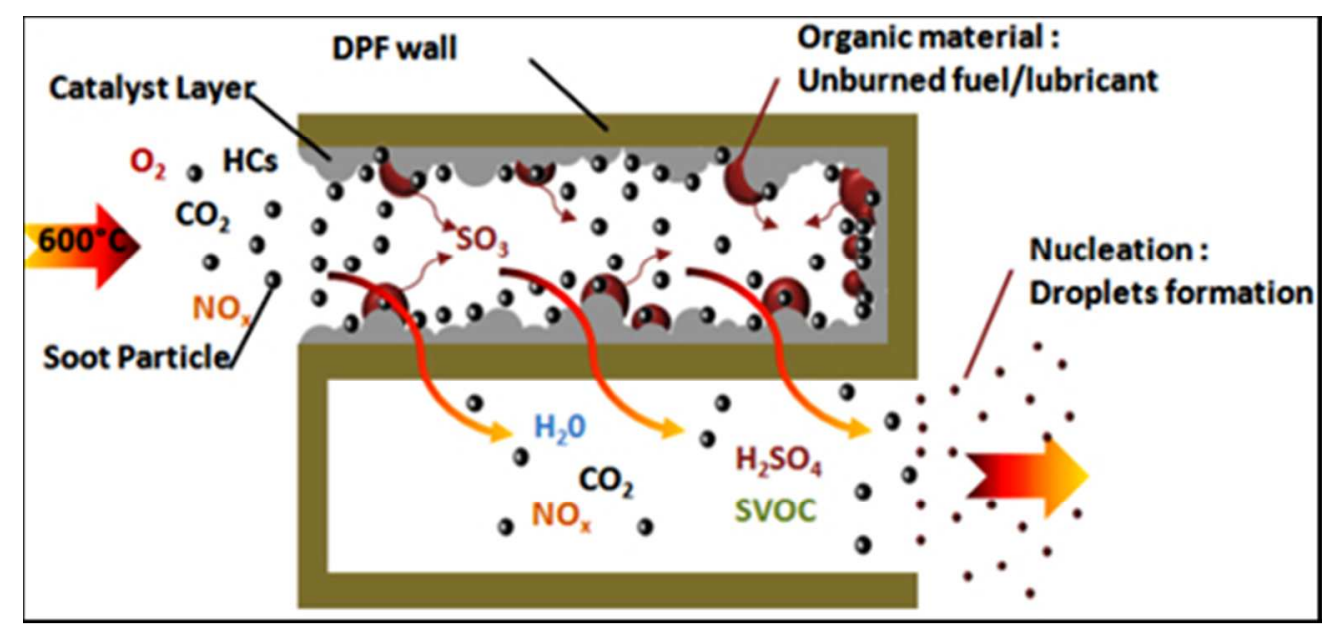

$84 \times 39 m m(150 \times 150$ DPI $)$ 


\section{Chassis dynamometer}

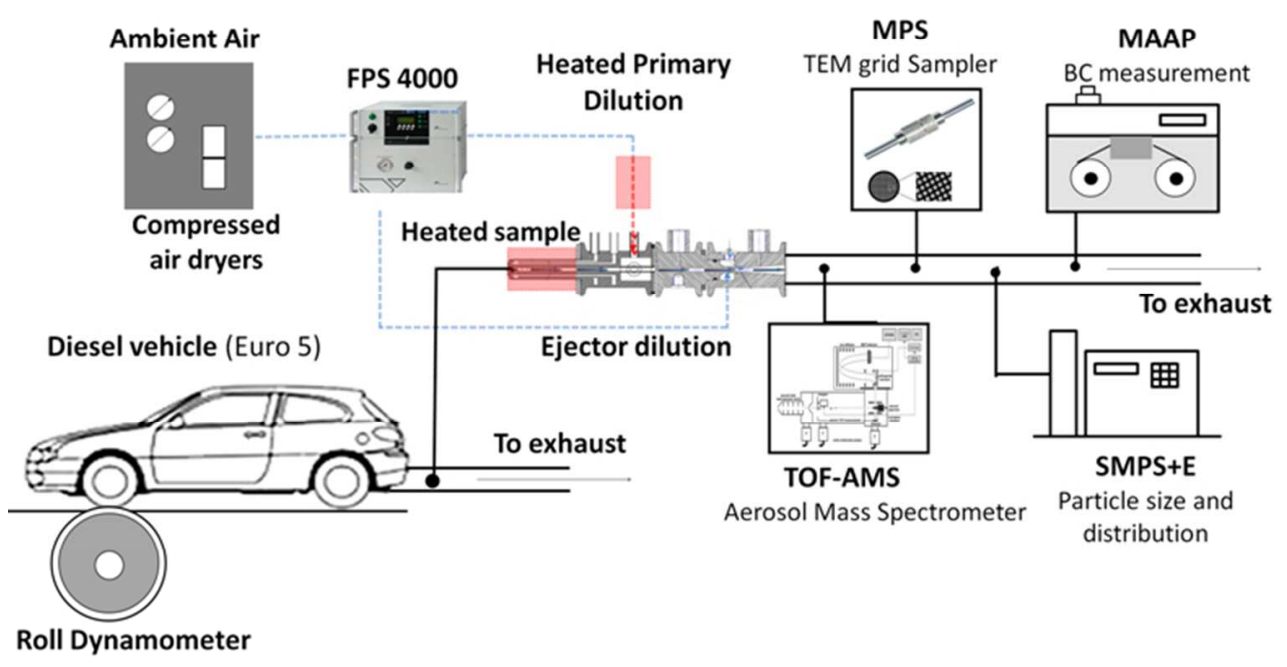

Figure 1. Schematic of the experimental set-up.

$260 \times 152 \mathrm{~mm}(78 \times 78$ DPI $)$ 


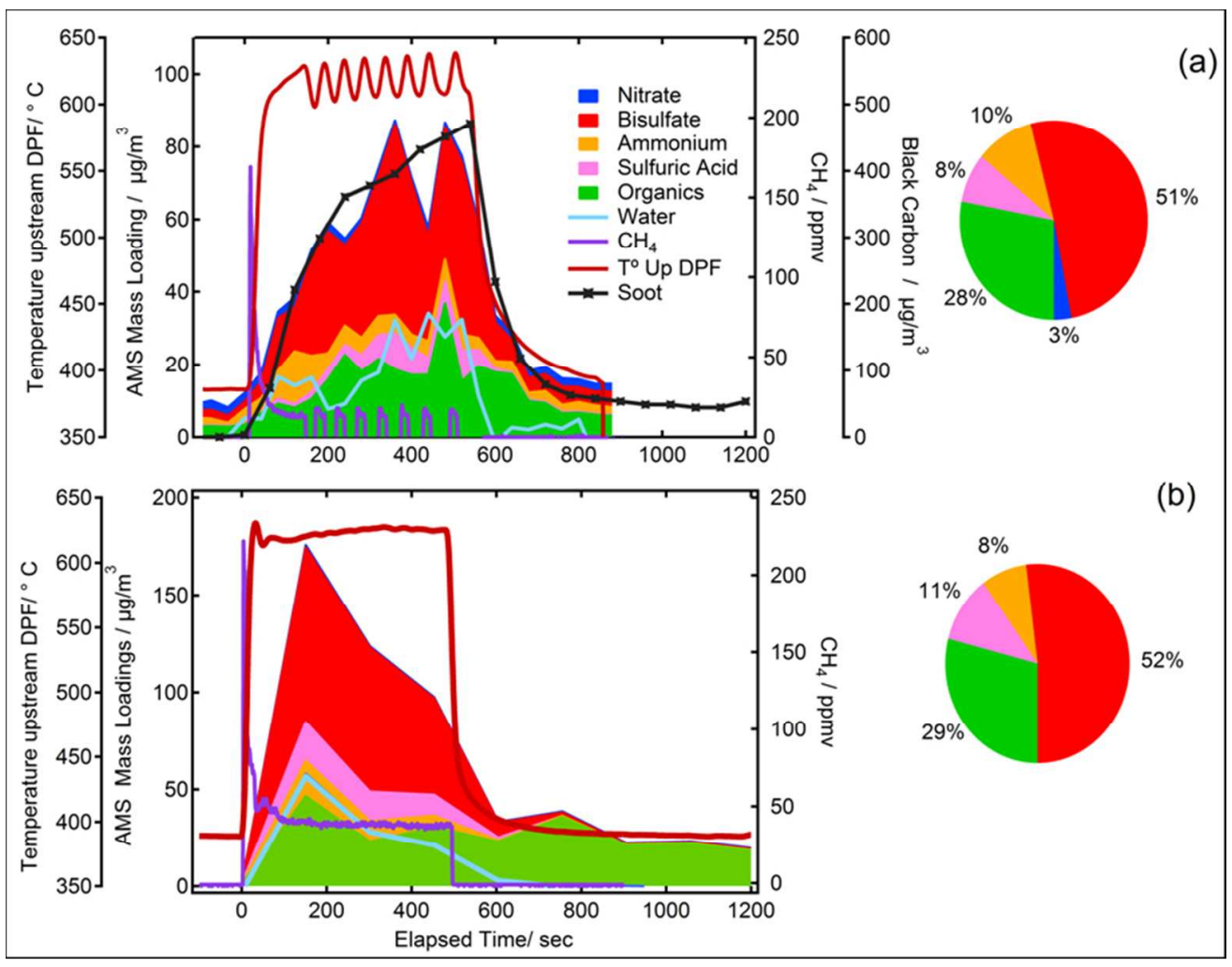

Figure 2. Time evolution and pie charts of the particle chemical composition during the first regeneration for the (a) FBC-DPF and (b) CDPF vehicle, respectively. Temperature upstream DPF and methane emission for the two regenerations are also presented.

$154 \times 120 \mathrm{~mm}(150 \times 150 \mathrm{DPI})$ 


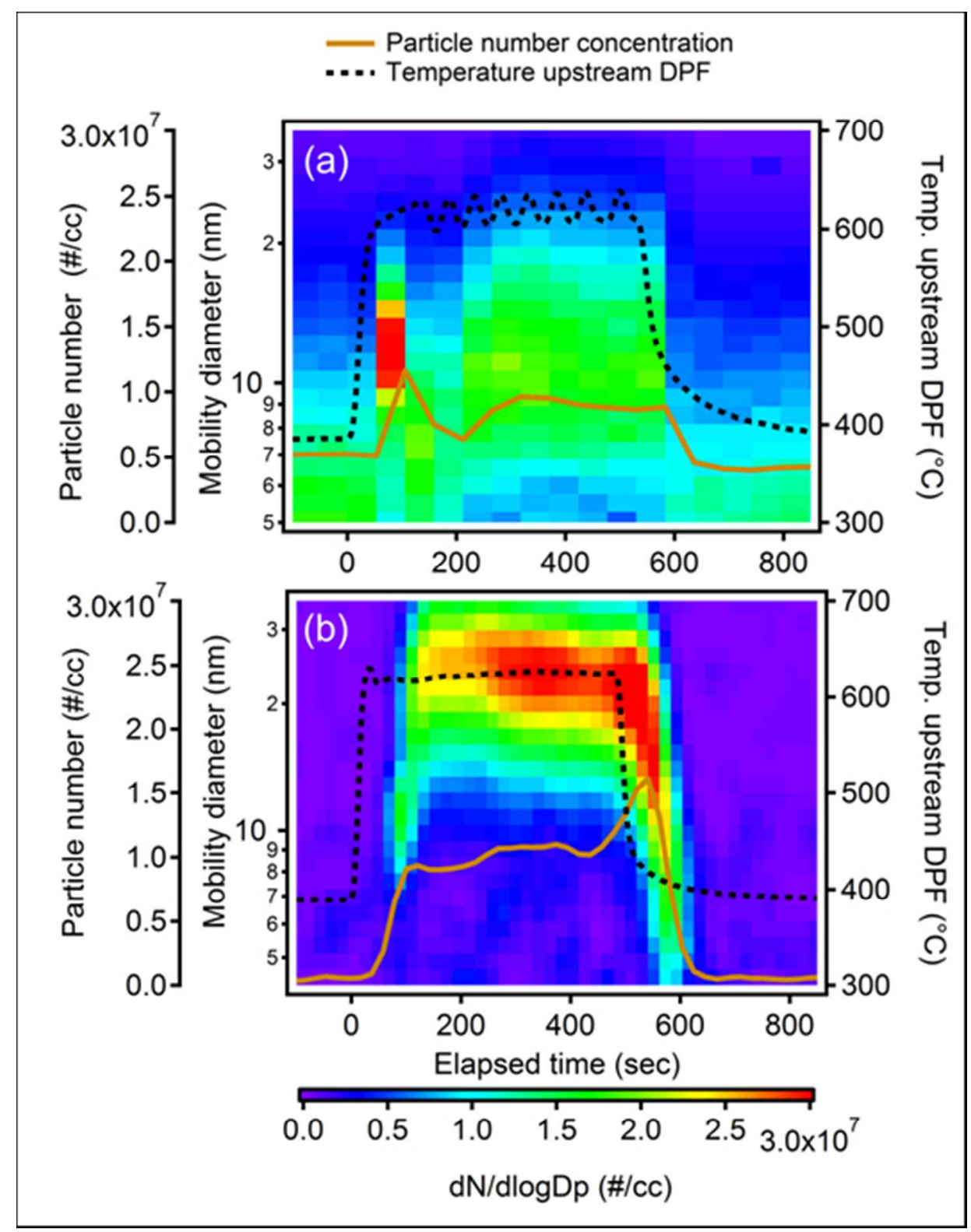

Figure 3. SMPS+E measurements - temporal evolution of ultrafine particles (mobility diameter below 35 $\mathrm{nm}$ ) concentration and size distribution during the first regeneration event of the (a) FBC-DPF and (b) CDPF vehicles, respectively.

$90 \times 115 \mathrm{~mm}(150 \times 150 \mathrm{DPI})$ 

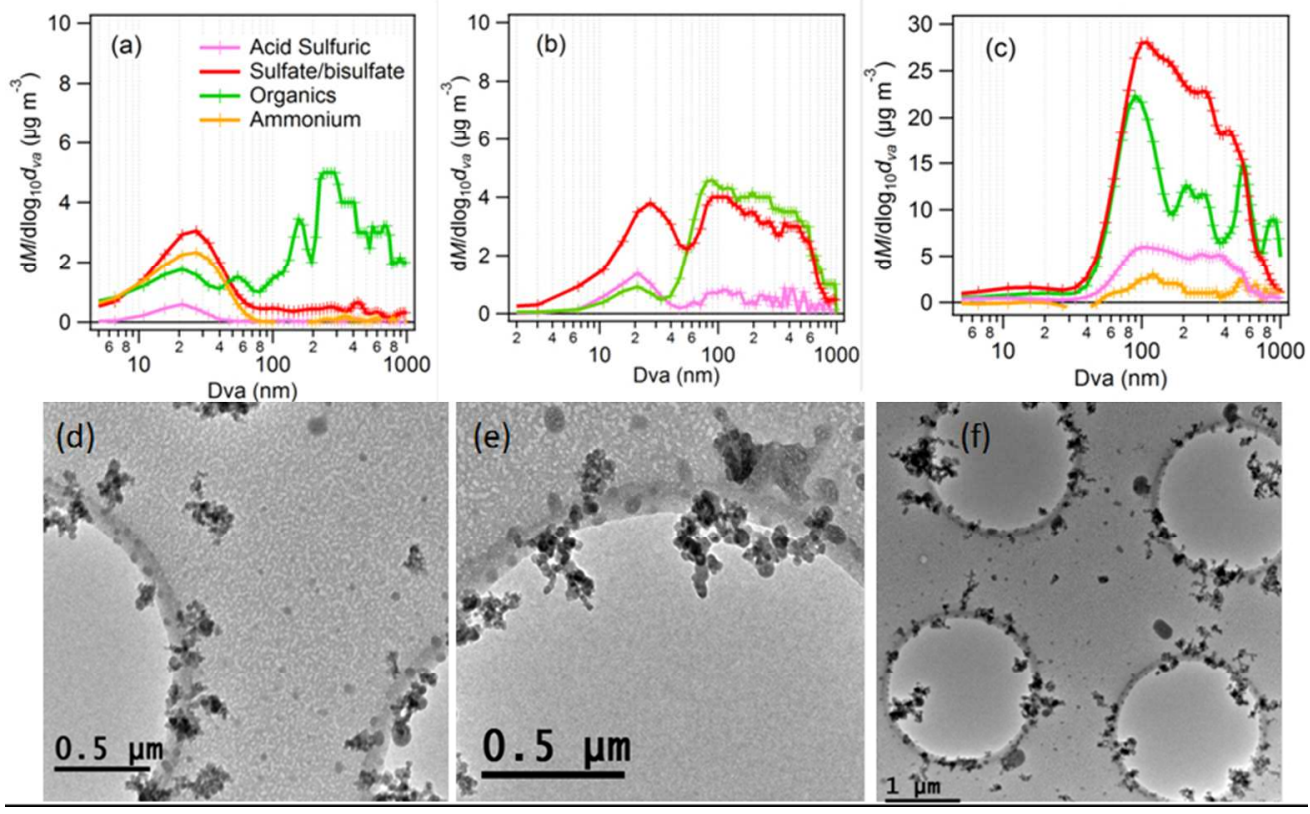

Figure 4. Particle size distribution and morphology during the regeneration of the FBC-DPF vehicle : chemically resolved particle aerodynamic vacuum diameter taken AMS data sampled PM collected in the period (a) $0-60 \mathrm{~s}$; (b) $180-300 \mathrm{~s}$; (c) $300-540 \mathrm{~s}$; TEM images collected in the period : (d) 180-300; (e) and (f) $300-540 \mathrm{~s}$.

$231 \times 144 \mathrm{~mm}(96 \times 96 \mathrm{DPI})$ 

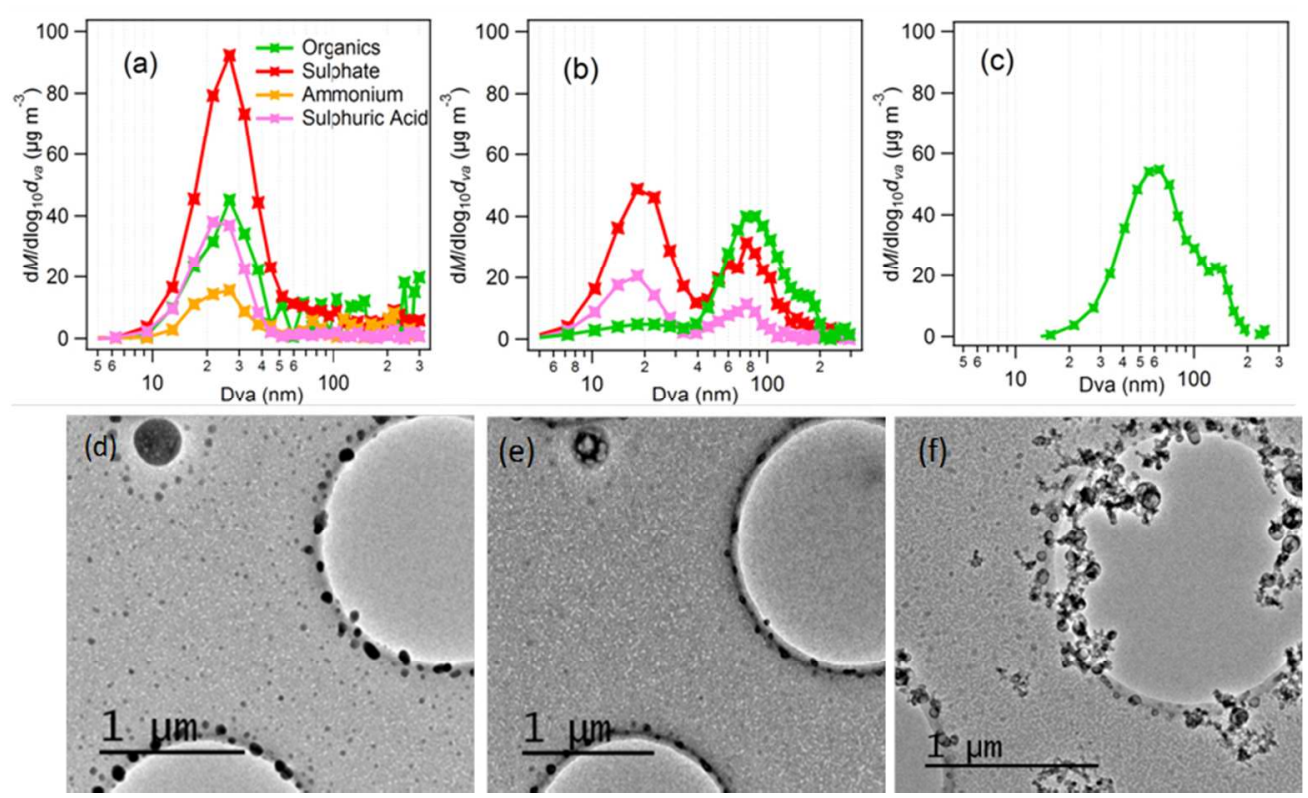

Figure 5. Particle size distribution and morphology during the regeneration of the CDPF vehicle : chemically resolved particle aerodynamic vacuum diameter taken AMS data sampled PM collected in the period (a) 0 $120 \mathrm{~s}$; (b) $240-360 \mathrm{~s}$; (c) $900-1020 \mathrm{~s}$; TEM images samples collected in the period : (d) $0-120 \mathrm{~s}$; (e) and (f) $240-360 \mathrm{~s}$.

$238 \times 143 \mathrm{~mm}(96 \times 96$ DPI) 
Table 1: Vehicle specifications

\begin{tabular}{|c|c|c|}
\hline & Diesel FBC-DPF & Diesel CDPF \\
\hline Weight $(\mathrm{kg})$ & 1300 & 1200 \\
\hline Mileage (km) & 28817 & 16100 \\
\hline Emissions standard & Euro 5 & Euro 5 \\
\hline Engine displacement (cc) & 1560 & 1461 \\
\hline Number of cylinders & 4 & 4 \\
\hline Rated power (kW) & 84 & 66 \\
\hline Peak torque (Nm) & 270 & 200 \\
\hline Fuel Delivery & common rail & Common rail \\
\hline After-treatment & Close-coupled DOC+FBC-DPF & Underfloor DOCs+CDPF \\
\hline
\end{tabular}

